\title{
Back-thrusting in Lesser Himalaya: Evidences from magnetic fabric studies in parts of Almora crystalline zone, Kumaun Lesser Himalaya
}

\author{
Amar Agarwal ${ }^{1, *}$, K K Agarwal ${ }^{2}$, R Bali ${ }^{2}$, Chandra Prakash ${ }^{2}$ and Gaurav Joshi ${ }^{2}$ \\ ${ }^{1}$ Laboratorio de Paleomagnetismo, Instituto de Geofisica, UNAM, Mexico City, Mexico. \\ ${ }^{2}$ Centre of Advanced Study in Geology, University of Lucknow, Lucknow, India. \\ ${ }^{*}$ Corresponding author.e-mail: amar@daad-alumni.de
}

The present study aims to understand evolution of the Lesser Himalaya, which consists of (meta) sedimentary and crystalline rocks. Field studies, microscopic and rock magnetic investigations have been carried out on the rocks near the South Almora Thrust (SAT) and the North Almora Thrust (NAT), which separates the Almora Crystalline Zone (ACZ) from the Lesser Himalayan sequences (LHS). The results show that along the South Almora Thrust, the deformation is persistent; however, near the NAT deformation pattern is complex and implies overprinting of original shear sense by a younger deformational event. We attribute this overprinting to late stage back-thrusting along NAT, active after the emplacement of ACZ. During this late stage back-thrusting, rocks of the ACZ and LHS were coupled. Back-thrusts originated below the Lesser Himalayan rocks, probably from the Main Boundary Thrust, and propagated across the sedimentary and crystalline rocks. This study provides new results from multiple investigations, and enhances our understanding of the evolution of the ACZ.

\section{Introduction}

The continental-continental collision of the Indian and Asian plates, $\sim 55 \mathrm{Ma}$ ago, motored the evolution of the $\sim 2400 \mathrm{~km}$ long belt of the Himalaya mountain chain, which is the loftiest in the world (Gansser 1964; Molnar and Tapponnier 1975; Valdiya 1998). The collision shortened the crust and developed three major south-verging thrust systems known as Main Central Thrust $(\mathrm{MCT})$ (active from $20.8 \pm 1.1$ to $15.0 \pm 2.4 \mathrm{Ma}$, Tobgay et al. 2012), Main Boundary Thrust (MBT) ( 11 Ma, Meigs et al. 1995), and Himalayan Frontal Thrust (HFT) (initiation age between 500 and $100 \mathrm{Ka}$, Thakur 2013), from north to south respectively (see Seeber and Armbruster
1981; Srivastava and Mitra 1994; Mukherjee et al. 2015; Dubey 2014). The MCT and MBT delineate the Lesser Himalayan sequence in Kumaun region from the Higher Himalaya in north and the Siwalik (sub-Himalaya) in south, respectively (Nakata 1989; Jayangondaperumal et al. 2010). The sedimentary formations of the Lesser Himalayan sequence (LHS) are tectonically overlain by several klippen consisting of largely amphibolite facie metamorphic rocks, and intrusive and basement granites, belonging to the Precambrian Almora group. The Almora group consists of granite, granodiorite and augen gneiss that are intruded into Saryu, Gumalikhet and Munsiari formations (Valdiya 1980). The intrusive and basement granites within the klippen have been dated

Keywords. Almora crystalline zone; Lesser Himalaya, back-thrusting; AMS. 
as $560 \pm 20 \mathrm{Ma}$ and $1865 \pm 60 \mathrm{Ma}$, respectively (Rb/Sr whole rock; Trivedi et al. 1984). On the one hand, some workers established the klippen as remnants of a once more extensive Munsiari thrust sheet, which lies structurally below the MCT (e.g., Valdiya 1980; Srivastava and Mitra 1994; Moharana et al. 2013). On the other hand, Jayangondaperumal and Dubey (2001) proposed that the klippen are pop-up or para-autochothnous.

\subsection{Geological setting}

The Almora klippen, also known as the Almora Crystalline Zone (ACZ), is the largest among all Lesser Himalayan thrust sheets. The intensely deformed ACZ trends WNW-ESE and is separated from the Damta-Tejam Group of rocks in the north and the sedimentary Krol belt in south by the North Almora Thrust (NAT) and South Almora Thrust (SAT), respectively (Valdiya 1980) (figure 1). Another important tectonic plane referred to as Mukteshwar dislocation (MD) or as Ramgarh Thrust/Uprari Thrust (Valdiya 1980; Robinson and Pearson 2013) is exposed in the north of SAT (figure 1).

The Almora crystalline zone is regionally folded into a giant synform having approximately an E-W axis. The southern limb of the Almora synform, with north dipping metamorphic rocks, has been divided into two: a lower Ramgarh Formation in the south (with mylonites, garnetiferous micaschist, inter-bedded quartzite and phyllites, some lenticular exposers of gneisses and thin bands of amphibolites), separated by the MD, and from an upper Mukteshwar Formation in the north with quartzites, garnetiferous chlorite schists and subordinate phyllites and gneisses (Bhattacharya and Agarwal 1985; Agarwal 1994; Bali and Agarwal 1999). The rocks are usually trending ESE-WNW and dipping $\sim 30^{\circ}$ towards north in the southern limb and around $50^{\circ}$ or more in the northern limb.

The two tectonic contacts, NAT and SAT separate the ACZ from the sedimentaries in the north and the south, respectively. A fairly thick zone of the mylonitic rocks (6-8 $\mathrm{km}$ wide) fringing the SAT (Bhattacharya and Agarwal 1985), falling in the Ramgarh Belt of Valdiya (1980), and another thin zone of mylonites bordering the NAT (Bali and Agarwal 1999) are present on the two sides. The SAT can be correlated with the Ramgarh Thrust of Valdiya (1980) and overlying rock units between SAT and Uprari Thrust (UT) can also be referred to the Ramgarh Belt. However, a variety of other rock types, viz., garnetiferous mica-schist, quartzite, phyllites, occasionally gneisses and gneissic granites, and thin bands of amphibolites with well-developed planar and linear fabrics are

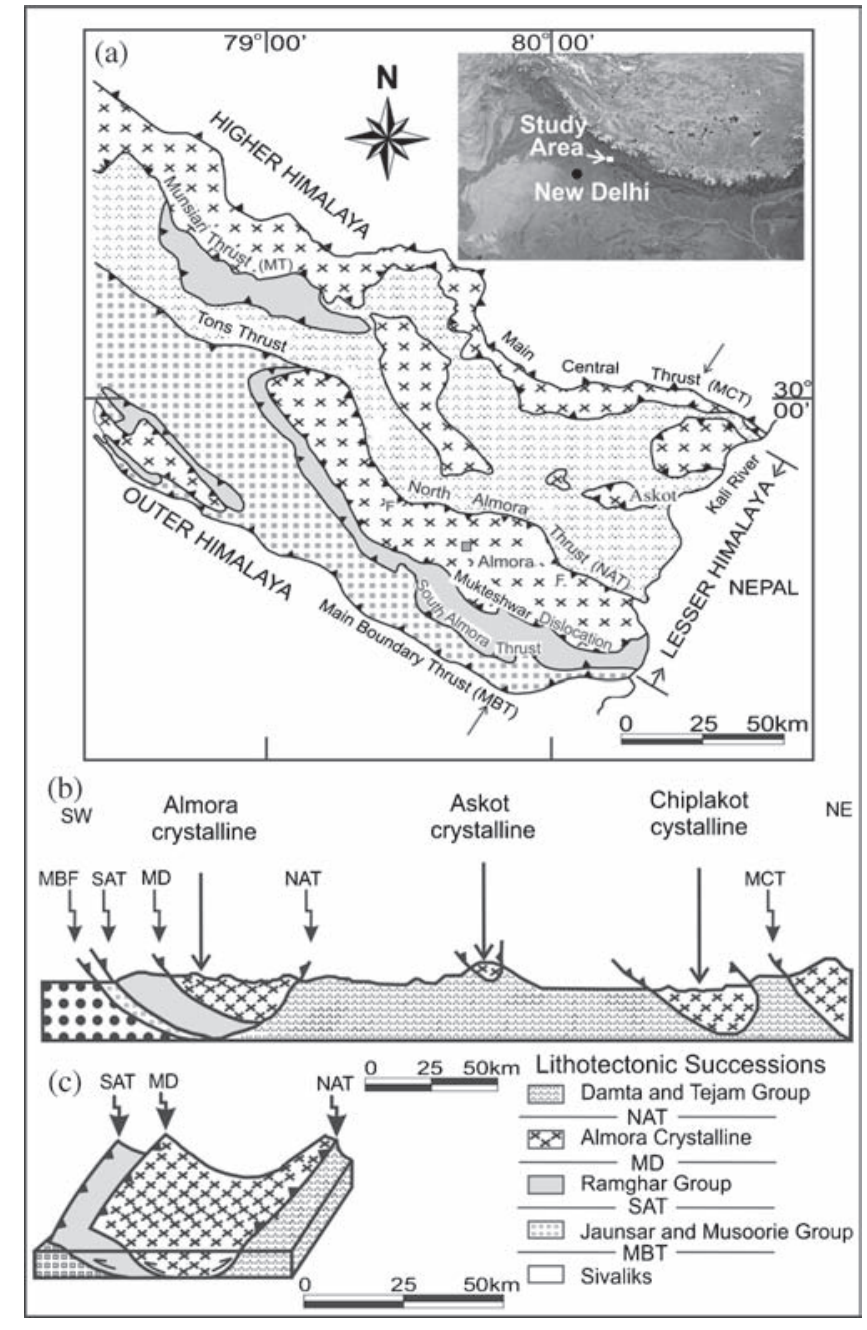

Figure 1. (a) Geological map of the Kumaun Lesser Himalaya showing regional extent of the Almora crystalline zone and other lithotectonic units (modified after Valdiya 1980). The arrows mark the cross-section line. (b) Generalised cross section of Kumaun Lesser Himalaya showing different lithounits and major thrust sheets and (c) tectonic disposition of Almora thrust sheet (Agarwal 1994; Pant et al. 2012), where 'MD' is Mukteshwar Dislocation and 'MCT' is Main Central Thrust. Note that the Damta and Tejam Group and the Jaunsar and Mussoorie Group belong to the inner and the outer Krol Belt, respectively.

also present. A variety of structural elements have been observed, e.g., small scale folds, shear zones (mainly showing overall top-to-south sense of shear, but also show top-to-north sense of shear occasionally along the northern limb near NAT) and other minor structures.

\subsection{Motivation}

Unlike the strike slip tectonics-dominated syntaxes at the two sides, the Kumaun Lesser Himalaya lies near the central part of the Himalayan belt 
and is, therefore, a critical area for studying the typical characteristics of the Himalayan fold-andthrust belt (Srivastava and Mitra 1994) and brittle deformation (Mukherjee and Koyi 2010a, b). Some published reports suggest that the NAT and SAT are two exposures of the same folded solethrust, over which the ACZ was thrust south from the Munsiari Formation (Valdiya 1980; Thakur 1992; Agarwal 1994; Srivastava and Mitra 1994); while the others treat NAT as the thrust contact between inner and outer Lesser Himalaya (Ahmad et al. 2000). Furthermore, some reports propose that since the western edge of NAT is juxtaposed with Tons thrust, both of them are exposure of the same thrust (Célérier et al. 2009a, b; Webb 2011); however, the emplacement relations are still unclear. Furthermore, backthrusting in the Himalayan collisional zone is significant to appreciate that a bivergent kinematics rather than a monovergent deformation operated in this orogeny (e.g., Bose and Mukherjee 2015). A comparative study of the deformation structures and magnetic fabrics may, therefore, reveal the similarities and differences in the deformation mechanism active at the NAT and SAT. It is important to note that there are no published or established ages for NAT and SAT. The comparison may further help in understanding the evolution of Lesser Himalaya in general and ACZ in particular.

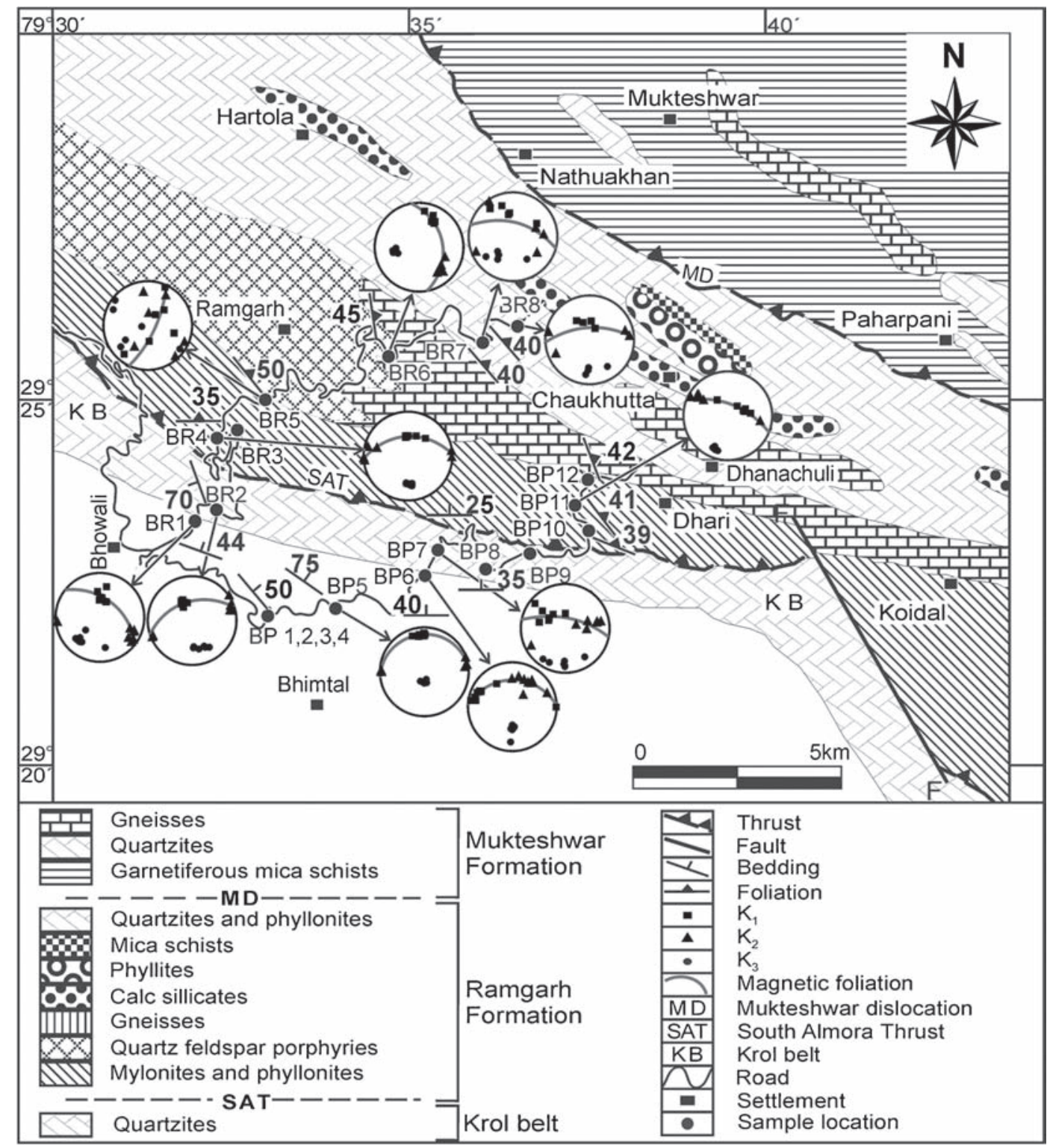

Figure 2. Geological map of the Bhowali-Ramgarh and Bhimtal-Dhanachuli section across the SAT, modified after Bhattacharya and Agarwal (1985). The map shows geological units, their trends and magnetic foliations, and the sample locations. 


\section{Methodology}

\subsection{Field based studies and sampling}

The orientation of the beds and the metamorphic foliation were recorded by a geological compass. Block samples, oriented using a compass, were collected from each site. A minimum of five cylindrical cores $(25.4 \mathrm{~mm}$ in diameter and $22 \mathrm{~mm}$ in length) were drilled from each block sample in the laboratory.

Geological map for the study area near SAT (figure 2) has been modified after Bhattacharya and Agarwal (1985). Geological map of the study area near NAT, the Dhaulchchina-Goniagad road section, has been prepared during the present study (figure 3).

\subsection{Rock magnetic measurements}

For magnetic fabric studies, the AMS was measured using a KLY-4S Kappabridge (AGICO,
Brno, Czech Republic) at Department of Strukturgeologie und Tektonophysik, Institutfür Angewandte Geowissenschaften, Karlsruher Institutfuer Technologie, Karlsruhe, Germany. The data were processed through the Anisoft 4.2 software, and plotted in lower hemisphere stereographic projections. We calculate the AMS parameters, such as mean bulk susceptibility $\left(k_{\mathrm{m}}\right)$; corrected degree of magnetic anisotropy $\left(P^{\prime}\right)$; mean of shape factor of AMS ellipsoid $\left(T_{\text {mean }}\right)$. The following equations, after Tarling and Hrouda (1993), represent these parameters:

$$
\begin{gathered}
k_{\mathrm{m}}=\left(k_{1}+k_{2}+k_{3}\right) / 3 \\
P^{\prime}=\exp \sqrt{ }\left[2\left(\eta_{1}-\eta_{\mathrm{m}}\right)^{2}+\left(\eta_{2}-\eta_{\mathrm{m}}\right)^{2}+\left(\eta_{3}-\eta_{\mathrm{m}}\right)^{2}\right] \\
T_{\text {mean }}=\left(2 \eta_{2}-\eta_{1}-\eta_{3}\right) /\left(\eta_{1}-\eta_{3}\right)
\end{gathered}
$$

where

$$
\eta_{1}=\ln k_{1} ; \quad \eta_{2}=\ln k_{2} ; \quad \eta_{3}=\ln k_{3}
$$

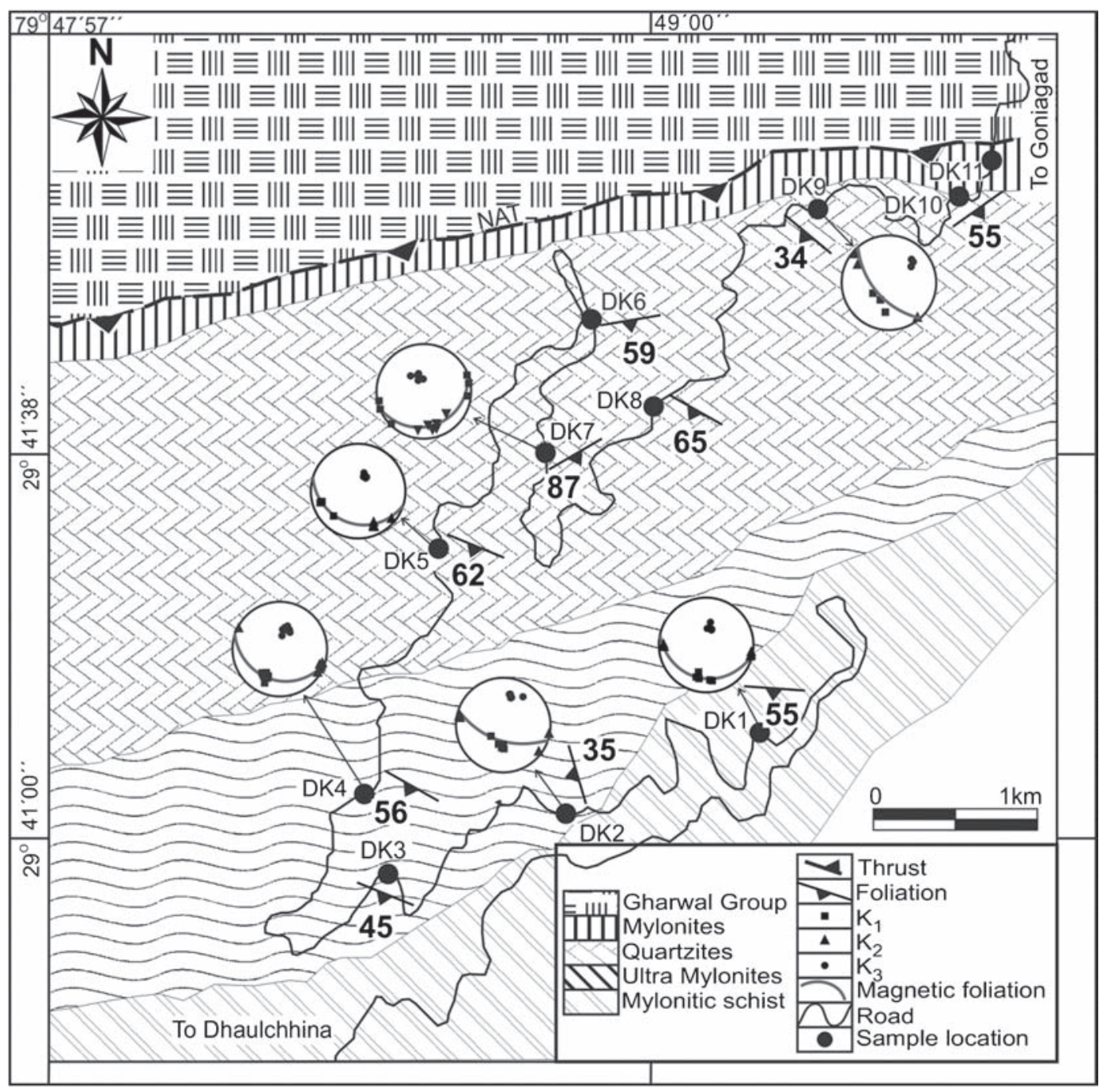

Figure 3. Geological map of Dhaulchhina-Goniagad section near NAT. The map shows geological units, their trends and magnetic foliations, and the sample locations. 
and

$$
\eta_{\mathrm{m}}=k_{2}\left[\left(\eta_{1}\right)\left(\eta_{2}\right)\left(\eta_{3}\right)\right]^{1 / 3} .
$$

We denote the maximum, intermediate and minimum principal magnetic susceptibility axes as $k_{1}$, $k_{2}$ and $k_{3}$. The $T_{\text {mean }}, k_{\mathrm{m}}$ and $P^{\prime}$ were studied as a function of distance from the thrusts, SAT and NAT. Furthermore, we plotted $T_{\text {mean }}$ against $P^{\prime}$ (Jelinek 1981) and $k_{\mathrm{m}}$ against $P^{\prime}$ to understand the relationship among them.

For investigating the magnetic mineralogy, temperature dependent low-field magnetic susceptibility $(\chi-T)$ experiments were carried out. The measurements were done in two runs on powdered samples using a Kappabridge (KLY-4S) (AGICO, Brno, Czech Republic) at Department of Strukturgeologie und Tektonophysik, Institutfür Angewandte Geowissenschaften, Karlsruher Institutfuer Technologie, Karlsruhe, Germany. For low temperature $\left(-194^{\circ} \mathrm{C}\right.$ to room temperature $)$ measurements, the Kappabridge was equipped with CS-L (AGICO, Brno, Czech Republic) cryostat and the sample was cooled to $-194^{\circ} \mathrm{C}$ using liquid nitrogen, which was then flushed out of the holder using a blast of argon. The bulk susceptibility of the sample was measured as it gradually warmed up to the room temperature. For high temperature $\left(40^{\circ}-700^{\circ} \mathrm{C}\right)$ measurements, the Kappabridge was equipped with a CS-2 furnace (AGICO, Brno, Czech Republic). The sample was first heated from $40^{\circ}-700^{\circ} \mathrm{C}$ (at a rate of $10^{\circ} \mathrm{C} \mathrm{min}^{-1}$ ) and was then cooled back. The bulk susceptibility was measured during the entire cycle of heating and cooling. An argon environment (flow rate of $60 \mathrm{ml} \mathrm{min}{ }^{-1}$ ) was maintained in the sample holder to minimize the risk of oxidation of the sample while heating. The temperature of the sample was measured with a $\mathrm{Pt}$ resistance thermometer, placed within a distance of $1 \mathrm{~mm}$. The first derivative curve of the $\chi-T$ measurements was calculated to determine the Curie temperature $\left(T_{\mathrm{C}}\right)$ and Verwey transition temperatures $\left(T_{\mathrm{V}}\right)$. The reversibility of the $\chi-T$ curves was also tested.

\section{Results}

\subsection{Macroscopic observations on the rocks in $A C Z$}

ACZ comprises of quartzites, mica schists, garnetiferous mica schists, gneiss and their mylonitic products, belonging to Ramgarh Formation and Saryu Formation which commonly show up to amphibolite facie metamorphism (figure 1) (Valdiya 1980; Srivastava and Mitra 1994, 1996; Bhattacharya 1999; Joshi 1999; Joshi and Tiwari 2004, 2009).

Rocks north of SAT, dip northward; however, those to south of SAT and close to the MBF dip steeply $\left(35^{\circ}-75^{\circ}\right)$ in various directions (figure 2 ). In contrast, the rocks south of the NAT consistently dip south (figure 3). The northward dip of rocks north of SAT and southward dip of the rocks south of NAT agree to the synformal model of ACZ (figures 1c, 5). Deformation structures, such as boudins, tensional gashes, lateral ramps, large to small scale folds, formed at brittle-ductile transition are common in the studied area (cf. Bali and Agarwal 1999). ACZ rocks are deformed intensely into two 6-8 $\mathrm{km}$ thick mylonite zones along NAT and SAT. The mylonite zone along SAT is thicker and more intensely deformed than that along NAT. Previous pseudo-tachylite based studies are in agreement that SAT is more intensely deformed than NAT (Agarwal 1994; Agarwal et al. 2011). In vicinity of SAT, mylonites demonstrate both brittle and ductile top-to-south shear sense (figure $4 \mathrm{a}, \mathrm{b}$ ). While near NAT they mostly show top-to-south shear sense (figure 4c), however at few spots top-to-north shear sense is also recorded (figure 4d, e, supplementary figure S1). Generally the slip surfaces, $\mathrm{C}^{\prime}$-surfaces, make small angles $\left(25^{\circ}-35^{\circ}\right)$ with respect to the shear boundaries (Grasemann et al. 2003). In ACZ rocks, the angle between $\mathrm{C}^{\prime}$-surfaces and the shear boundaries is within this range (figure 4).

\subsection{Microscopic observations on the rocks in $A C Z$}

In general, the mylonites show a prominent schistosity defined by the alignment of ellipsoidal quartz and sometimes by feldspar grains and their aggregates. However, evidences of heterogeneous deformation due to variation in mechanical properties of the rock are common, such as rotation of quartz grains while fracturing of weaker biotites (figure 4f, g, h). In general, under the microscope the deformation ranges from brittle to semi-brittle in ACZ rocks. In coherence, Bali and Agarwal (1999) describe numerous grains that are plastically deformed or fractured. Grinding of larger quartz and plagioclase grains into smaller grains is common (figure 4f, g) (cf. Bali and Agarwal 1999). Along the SAT, in consequence to intense grinding, only a residue of fine grained, dark coloured material is observed and the clast density is very low, some times less than a couple of grains in a rock-thin section $\left(\sim 5 \mathrm{~cm}^{2}\right)$. These rocks may, thus, be classified as ultramylonites. The clast density increases gradually with distance from the thrusts. Larger quartz clasts, near the SAT, show delta $(\delta)$ (figure $4 \mathrm{f}$ ) and sigma $(\sigma)$ (figure $4 \mathrm{~g}$ ) structures. The ductile shear sense deduced from these grains is top-to-south. Chlorite and biotite as secondary minerals define secondary foliation. The chlorite and biotite have either a syn- or pre-deformation origin, because they demonstrate 

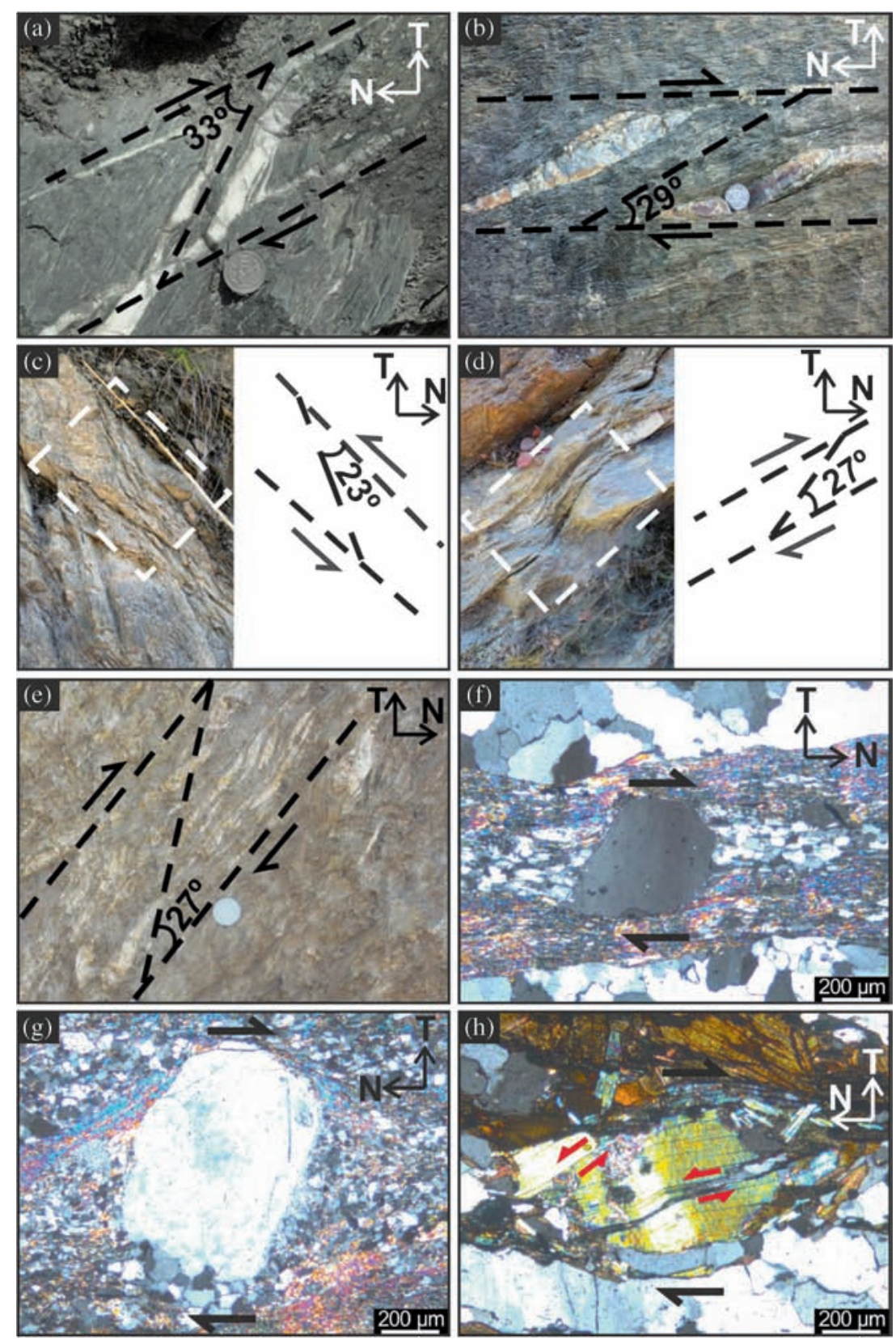

Figure 4. (a) Quartz veins in mylonites near SAT demonstrating top-to-south shear. Angle between $\mathrm{S}$ and $\mathrm{C}^{\prime}$ planes is $33^{\circ}$. (b) Garnitiferous quartz mica schist dipping $22^{\circ}$ towards 045 showing top-to-south shear sense along with a sheared quartz vein. Angle between $\mathrm{S}$ and $\mathrm{C}^{\prime}$ planes is $29^{\circ}$. (c) Shear zone showing top-to-south shear sense (white rectangle) in mylonites near NAT. Angle between S and $\mathrm{C}^{\prime}$ planes is $23^{\circ}$ (see Trouw et al. 2009 for similar examples). (d) Shear zone showing top-to-north shear sense (white rectangle) in mylonites, which is opposite to the general shear sense along NAT. Angle between $\mathrm{S}$ and $\mathrm{C}^{\prime}$ planes is $27^{\circ}$. (e) A shear zone visible near Kafligair village, developed in vicinity of NAT. The beds dip southwards. The sense of shear is top-to-north (up-dip). Angle between $\mathrm{S}$ and $\mathrm{C}^{\prime}$ planes is $27^{\circ}$. (f) Sigma structure formed by a dextrally rotated quartz grain and pressure shadow of fine grained mica. The structure shows a top-to-north shear sense. (g) Quartz grain in finer matrix forming a delta structure and showing dextral shear sense. (h) Mica-fish in micaseous quartzite near NAT showing a micro-shear zone, having a sinistral shear sense (black arrows), enclosed by dextral micro-shear zone. $\mathrm{N}$ and $\mathrm{T}$ mark the north and top of the images, respectively.

conspicuous shear zone microfabric. The chlorite grain from a sample near NAT is most interesting as it shows sinistral offset, antithetic with respect to the main dextral microshear zone (figure $4 \mathrm{~h}$ ). Since the micrograph is from an XZ (parallel with the lineation and perpendicular to the foliation) thin-section, which is oriented in its original position, the sinistral and dextral shear sense are analogous to top-to-north and top-to-south (cf. Trouw et al. 2009). 


\subsection{Magnetic fabrics in rocks near SAT and NAT}

The rocks near SAT show oblate magnetic fabrics (figure S2) which, in general, strike E-W (figure 2) and have moderately to gently plunging northwardly dip (figure 5). In accordance, $k_{3}$ axis plunge moderately southwards (figure 5). Similar to those near the SAT, rocks in vicinity of the NAT have oblate magnetic fabrics (figure S2) striking roughly $\mathrm{E}-\mathrm{W}$ (figure 3 ). Most $k_{3} \mathrm{~s}$ have steep $\mathrm{N}$ to NNE plunge, but a few plunge steeply to SE (figure 5). Along the SAT and NAT the magnetic lineation has a down-dip attitude with respect to the magnetic and field foliation.

It is noteworthy that with decreasing distance from the thrusts, SAT or MD, the magnetic fabrics become progressively less oblate, in other words more neutral ( $T_{\text {mean }}$ decreases on closeness with SAT and MD; figure 6). However, no such relation is observed between $T_{\text {mean }}$ and distance from NAT (figure 6). While $k_{\mathrm{m}}$ increases with distance from SAT; no such relationship is observed in case of NAT (figure 7). $P^{\prime}$, on the other hand, shows
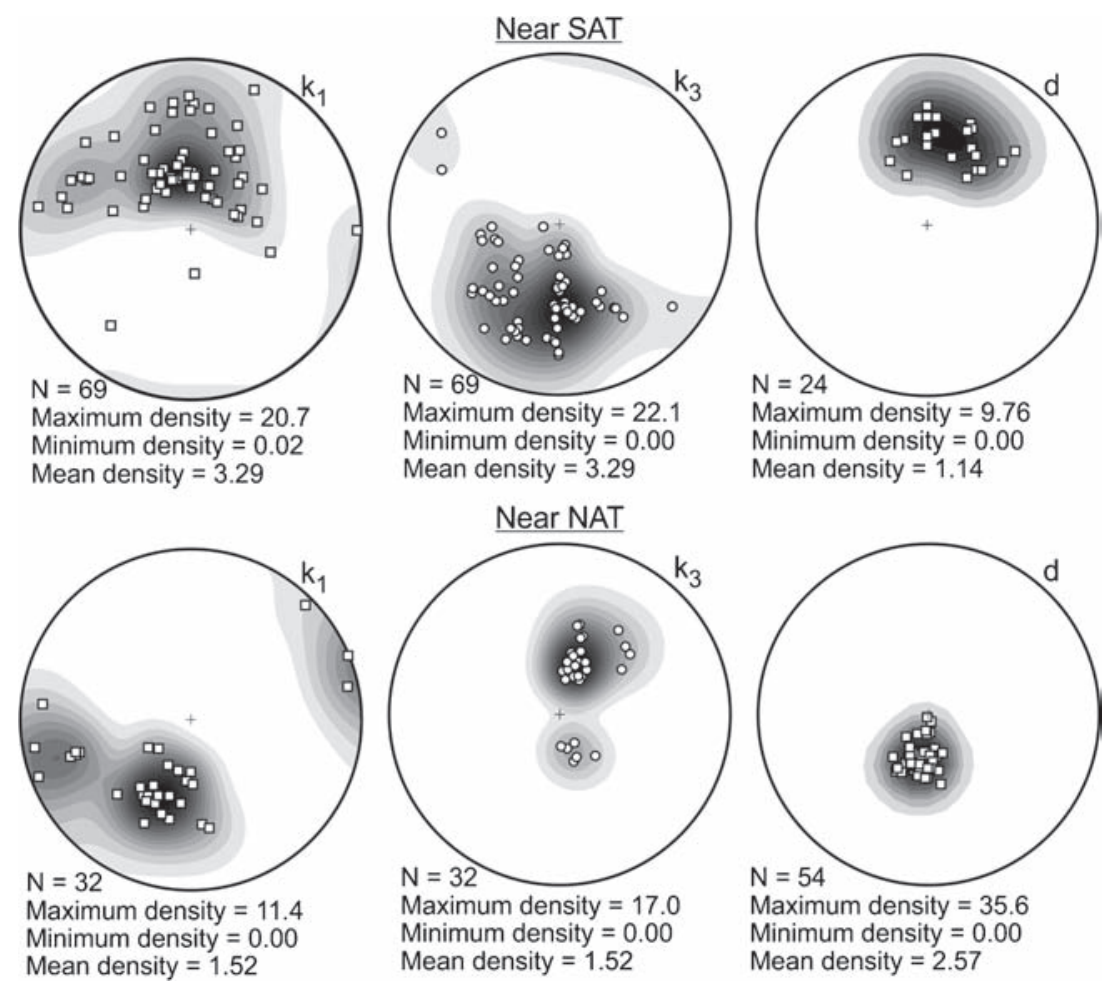

Figure 5. Lower hemisphere projections of the maximum $\left(k_{1}\right)$ and minimum $\left(k_{3}\right)$ principal magnetic susceptibility axes. All samples were collected near the SAT and the NAT. The dip (d) of the beds/metamorphic foliation is also presented. The density contours are calculated by cosine sum method, considering 20 as cosine exponent and 15 cosine intervals.

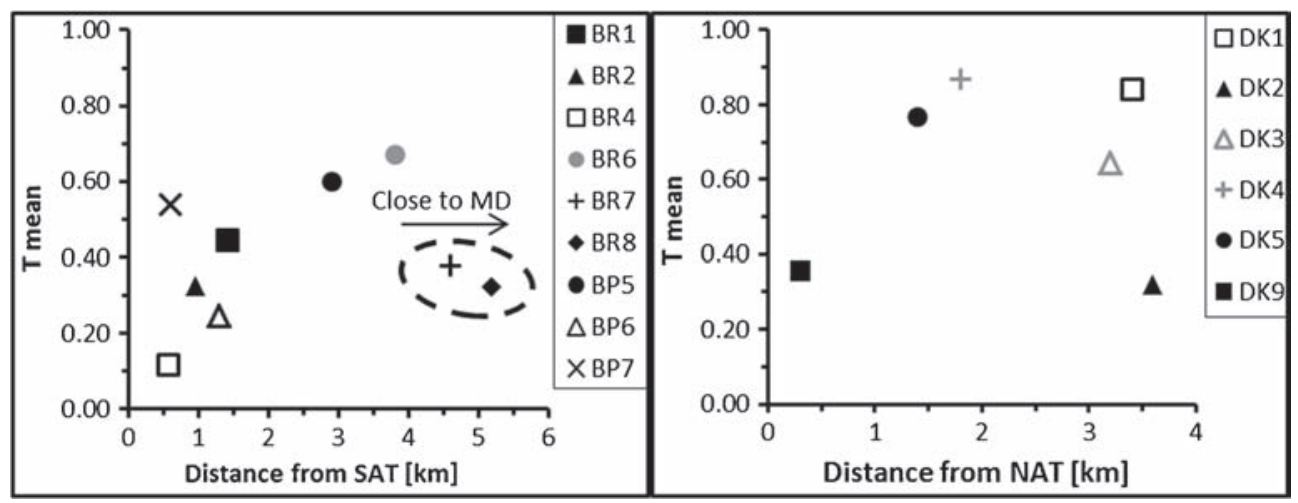

Figure 6. Graphs showing variation in shape factor of the AMS ellipsoid $\left(T_{\text {mean }}\right)$ with distance from the thrusts. $T_{\text {mean }}$ increases with distance from SAT until the sampling sites get too close to MD, when $T_{\text {mean }}$ decreases. Each data point is a mean of at least five samples, collected from a sampling site. 
direct correlation with the distance from both SAT and NAT. For example, $P^{\prime}$ increases with distance from the SAT and the NAT (figure 8). Increase in $P^{\prime}$ with distance from the thrusts implies that the rocks are becoming magnetically less anisotropic due to thrusting. To the north of the SAT, in three farthest samples, $P^{\prime}$ decreases with distance (figure 8). Gradually increasing closeness of these samples with the MD may have caused decrement in $P^{\prime}$ (figure 8).

In all lithologies near SAT and NAT, presence of only paramagnetic minerals is revealed by absence of Verwey and Curie transition and the substantial noise in the $\chi-T$ curves (figure $9 \mathrm{a}, \mathrm{b}$ ). In consequence these rocks have low magnetic susceptibility, typically less than $1.00 \times 10^{-3}$ SI units

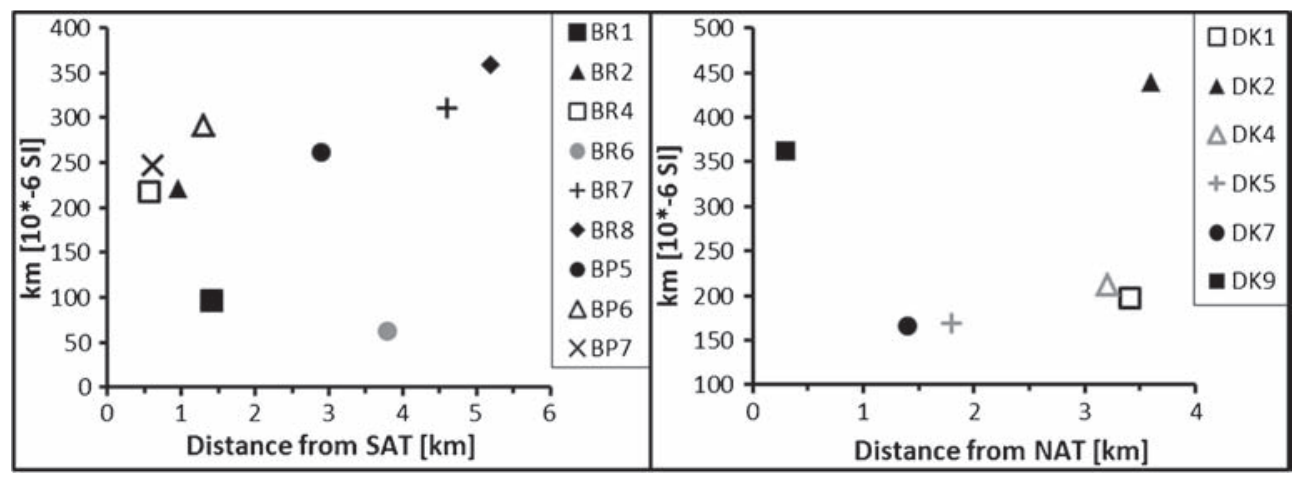

Figure 7. Graphs showing variation in mean of bulk susceptibility $\left(k_{\mathrm{m}}\right)$ with distance from the thrusts. $k_{\mathrm{m}}$ increases with distance from the SAT. Each data point is a mean of at least five samples, collected from a sampling site.

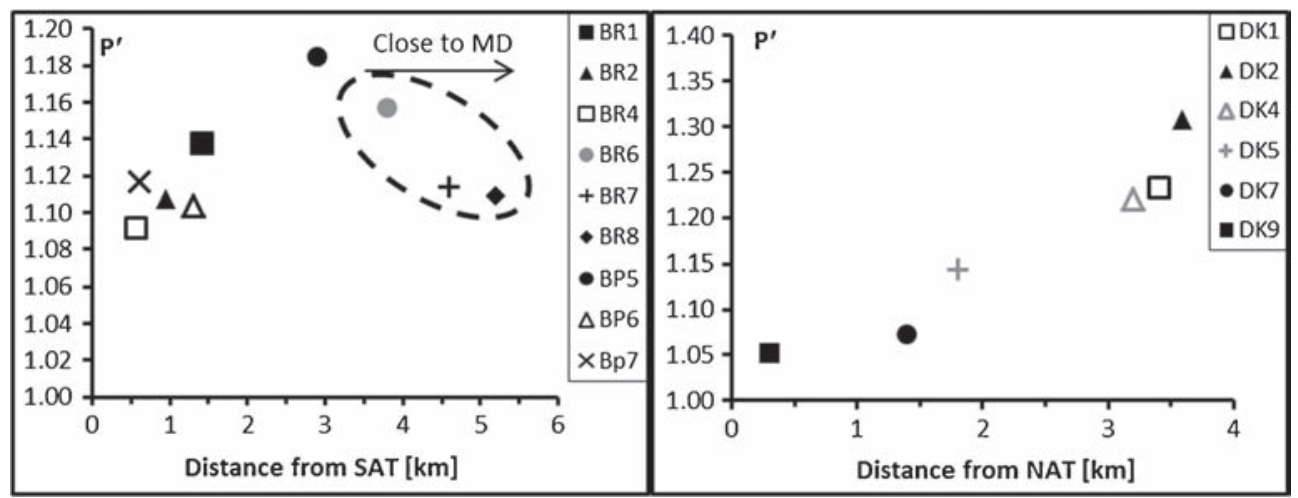

Figure 8. Graphs showing increase in mean of corrected magnetic anisotropy $\left(P^{\prime}\right)$ with distance from the SAT and NAT, until, in the case of SAT the sampling sites were too close to the MD. Each data point is a mean of at least five samples, collected from a sampling site.

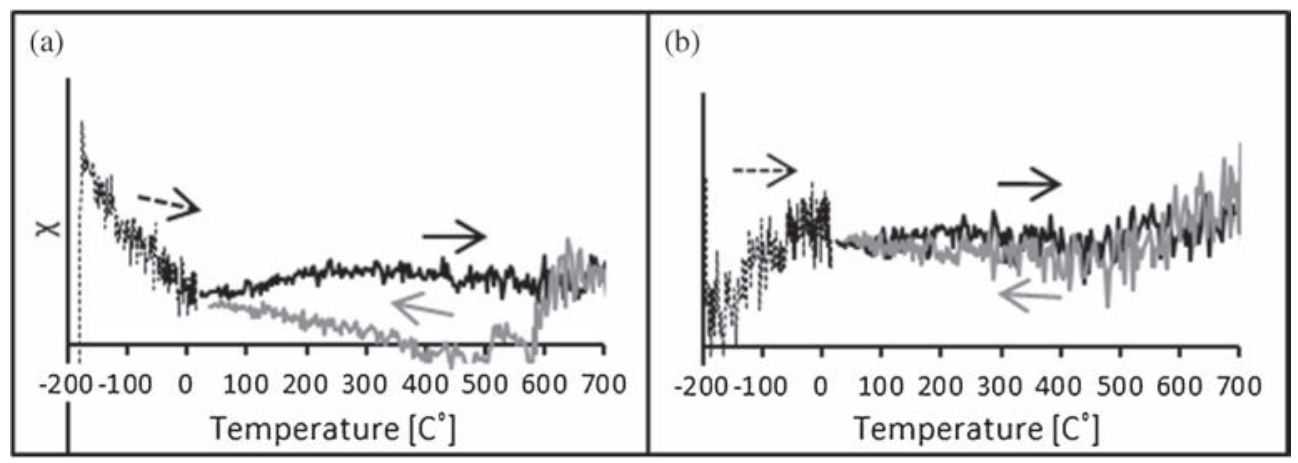

Figure 9. Susceptibility $(\chi)$ normalised to susceptibility at $40^{\circ} \mathrm{C}$ vs. temperature curves. The solid curves (black and grey) represent high temperature measurements, while the black dotted curve represents low temperature measurements. Representative curve for rocks (a) near the SAT and (b) near the NAT. 
(table S1). Occasionally in rocks near SAT, susceptibility in cooling curve (black dotted curve in figure 9a) is lower than in the heating curve (black and grey solid curves in figure 9a). Such a behaviour may be attributed either to destruction of paramagnetic phases during heating or to an artefact induced due to low susceptibilities (e.g., Petrovský and Kapička 2006; Agarwal et al. 2015). The peak in the beginning of cooling curve at about $-180^{\circ} \mathrm{C}$ is an artefact introduced by the cryostat (figure 9a).

\section{Discussion}

The Himalayan orogeny has led to more compression after the ACZ emplacement of Munsiyari Thrust either as remnants (Valdiya 1980; Srivastava and Mitra 1994, 1996) or as pop-up or para-autochothnous (Jayangondaperumal and Dubey 2001). The late stage compression may have superimposed the original rock and magnetic fabric, thus either overprinting or intensifying it. Comparison of field and magnetic foliation, and examination of deformation structures in field and under microscope may reveal the superimposition of the late stage deformation and thus decode information on the emplacement mode of the NAT.

\subsection{Structural trends of rocks in the $A C Z$}

Structures such as shear zones, plastically deformed quartz grains and meso-to-micro scale fractures were frequently observed. These brittle and plastic deformation structures and the distribution of mylonites in the ACZ indicate that the deformation regime possibly reached the brittle-ductile transition zone. The brittle-ductile transition was marked by development of $\mathrm{S}-\mathrm{C}^{\prime}$ fabric and shear band foliation (figure 4).

The deformation pattern near the SAT can be more-or-less well constrained. The beds and the metamorphic foliations consistently dip northwards (figures 2, 5), which agree well to the synformal model of the ACZ (e.g., Agarwal 1994; Agarwal et al. 2010). The shear zones and structures observed in field and under microscope demonstrate top-to-south shear sense (figure $4 \mathrm{a}, \mathrm{b}, \mathrm{g}$ ). This shear sense is in agreement with the southward thrusting model of ACZ (Jain and Anand 1988), and is common in most of the Himalayan terrains (Mukherjee et al. 2012).

The situation near the NAT is complex. Both the metamorphic and magnetic foliations consistently dip southwards (figure 5) which agrees well to the synformal model and southward thrusting of ACZ. However, some shear zones and structures observed in field and under microscope demonstrate top-tosouth shear sense; while the other demonstrate topto-north shear sense. Rheological complicacies and reorientation of shear zones can produce reverse shear (Mukherjee 2012). Although the top-to-south shear sense is more frequent and agrees to the southward thrusting model of ACZ, we cannot overlook the less common top-to-north shear sense, which is observed only in patches near NAT. The antithetic, top-to-north, shear sense may be argued as a flanking structure with reverse shear sense (e.g., Grasemann et al. 2003). However, the reverse shear sense is also observed in the magnetic fabrics, thus, suggesting that the top-to-north shear sense is not due to flanking.

Sporadic albeit conspicuous micro- and mesostructural evidences indicate that the top-to-north shear sense is younger and has overprinted the topto-south shear sense (figure 4f). This late stage deformation is antithetic to the original southward thrusting. However, absence of such structures near SAT implies that the younger episode of deformation was more active near the NAT. We therefore propose that, after the emplacement of $\mathrm{ACZ}$ as a thrust sheet, northern margin of the klippen thrust, NAT (i.e., the roof thrust) reactivated and back-thrusts developed to accommodate the continued compression. There are two possible origin of back-thrusts: (i) NAT suffered reactivation and inversion of shear sense. Thus the NAT 'modified' in to back-thrusts. A similar model was proposed by Agarwal (1994). (ii) Root of back-thrusts lies much below the ACZ and LHS, most probably at the Main Boundary Fault (MBF) and the NAT was not reactivated.

\subsection{Magnetic fabrics of rocks in $A C Z$}

The magnetic fabrics near the SAT dip northwards and $k_{3}$ vary in tend from SW to SE (figures 2,5 ). Near the NAT the magnetic fabrics strike E-W, most of which dip towards S (figures 3,5 ). These magnetic fabrics, near SAT and NAT, approximate the metamorphic foliation (figures 2,3 ). It is important here that, the orientation of sedimentary beds in ACZ is similar to the metamorphic foliation and the magnetic fabrics (figure 2). We therefore, ascribe such orientation of the magnetic fabrics to the synformal geometry of ACZ. The synformal curvature, introduced in the ACZ after its emplacement, rendered the field and the magnetic fabrics with similar trends. A small fraction of $k_{3}$, near the NAT, plunge SE (figure 5). This trend is reverse of the prominent southward plunge in ACZ, and can neither be explained by synformal geometry of ACZ nor by its south trusting. Along the SAT and NAT, the magnetic lineation has a downdip attitude with respect to the magnetic and field 
foliation. This may have been caused by shearing during the ductile deformation.

Shape and anisotropy of the AMS ellipsoid $\left(T_{\text {mean }}\right.$ and $\left.P^{\prime}\right)$ and the mean bulk susceptibility $\left(k_{\mathrm{m}}\right)$ decrease in vicinity of SAT and MD (figures 6, 7, 8). In spite of these conspicuous relationships of magnetic properties with distance from the SAT, we do not observe any relationship of $P^{\prime}$ with either $T_{\text {mean }}$ or $k_{\mathrm{m}}$ (figure $\mathrm{S} 2$ ). Lack of such relationships imply that the variation in the magnetic parameters with distance from the SAT is not due to intrinsic rock properties, such as change in grain size and/or in mineralogy, but owes itself to thrusting-related phenomenon. We attribute decrease in the magnetic properties, $k_{\mathrm{m}}, T_{\text {mean }}$ and $P^{\prime}$, to increase in brittle deformation and mylonitization with closeness to SAT. Brittle deformation may have fractured the paramagnetic carrier minerals. Absence of such relationships near NAT are, in particular, noteworthy and imply that during the emplacement of ACZ either the brittle deformation was active only along the SAT, or both along SAT and NAT but was subsequently obscured along NAT (figures $6,7,8$ ). We suggest that the previously proposed back-thrusting along NAT was realised as a swarm of thrusts, rather than a unique plane/zone. Deformation implied by them, therefore, lacked a systematic gradient with respect to distance from NAT, as was observed in the case of SAT. Lack of gradient meant that deformation intensity did not decrease continuously with distance from the NAT.

It may be concluded that, a relationship between magnetic parameters and distance from NAT, similar to that observed in case of SAT, was present after the emplacement of ACZ. However, later back-thrusting obscured these relationships and overprinted some $k_{3}$ such that their plunge changed from northward to southward.

\subsection{Evolution of $A C Z$}

We propose that the evolution of ACZ is marked by at least two stages, with characteristic metamorphic and mutually antithetic deformation pattern. The southward thrusting of the ACZ was accompanied by metamorphism that grew secondary paramagnetic minerals, such as chlorite, presumably by shear heating (Mulchrone and Mukherjee 2016). Due to southward thrusting all the mineral grains were preferentially aligned (e.g., Passchier and Trouw 1996) and a prominent metamorphic and magnetic foliation developed. It is important here that due to the southward thrusting, initial shear sense in ACZ was top-to-south, and the metamorphic and magnetic foliations had southward dip, with $k_{3}$ plunging northward. To accommodate further compression, due to active Himalayan orogeny, NAT reactivated and back thrusts developed. The reactivation motored the overprinting of the original top-tosouth shear sense with younger, antithetic, top-tonorth. The overprinting and younger shear sense is, thus, observed in shear zones and microstructures (figure $4 \mathrm{~d}, \mathrm{e}, \mathrm{f}, \mathrm{h}$ ) and in some $k_{3}$ with southward plunge (figure 5).

\section{Conclusions}

We compare the structures and rock magnetic properties of rocks near the SAT and NAT and discuss the origin of ACZ. The investigations reveal that

- magnetic fabrics of all the rocks in ACZ are carried by secondary paramagnetic minerals, such as chlorite, which are sometimes fractured.

- Near SAT the sedimentary beds and the metamorphic and magnetic foliations have similar orientation, i.e., northward dip. The situation near NAT is complex. Here the general trend of the magnetic and metamorphic fabric is southward dipping and corresponding $k_{3}$ plunge northward; however, some $k_{3}$ demonstrate a southward plunge.

- Deformation near SAT has a consistent top-tosouth shear sense. However, near NAT, both topto-south and top-to-north (at microscale and in the outcrop) shear sense are recorded, although the former is more common. We thus propose after the ACZ emplaced, Lesser Himalayan NAT was back-thrust.

The present study deals with the gap in our understanding of the evolution of ACZ. It provides an appropriate model to explain the present and previous observations from the sedimentary and crystalline rocks in Lesser Himalaya. It emphasizes on the need of exhaustive studies by employing parallel techniques, to unequivocally understand the evolution of Himalaya.

\section{Acknowledgements}

The work was supported by grants from Coordinación de la Investigación Científica, Mexico to AA and CSIR's Research Associate Program to CP. The authors (KKA, RB, GJ) are thankful to the Head, Centre of Advanced Study in Geology, Lucknow University, Lucknow, India for providing working facilities. Prof. L Valdivia is thanked for his suggestions. Dr S Mukherjee and the anonymous reviewer are thanked for their constructive criticism. 


\section{References}

Agarwal A, Kontny A and Greiling R O 2015 Relationships among magnetic fabrics, microfractures and shock pressures at an impact crater: A case study from Lockne crater, Sweden; J. Appl. Geophys. 114 232-243.

Agarwal K K 1994 Tectonic evolution of the Almora crystalline zone, Kumaun Lesser Himalaya: A reinterpretation; J. Geol. Soc. India 435.

Agarwal K K, Jahan N and Agarwal A 2010 Modification of fold geometry in Almora Crystalline Shear Zone, Lesser Himalaya, India; J. Geol. Soc. India 75 411-414.

Agarwal K K, Sharma A, Jahan N, Prakash C and Agarwal A 2011 Occurrence of pseudotachylites in the vicinity of South Almora Thrust zone, Kumaun Lesser Himalaya; Curr. Sci. 101431.

Ahmad T, Harris N, Bickle M, Chapman H, Bunbury J and Prince C 2000 Isotopic constraints on the structural relationships between the lesser Himalayan series and the high Himalayan crystalline series, Garhwal Himalaya; Geol. Soc. Am. Bull. 112 467-477.

Bali R and Agarwal K K 1999 Microstructures of mylonites in the Almora Crystalline Zone, Kumaun Lesser Himalaya; In: Gondwana Research Group Memoir (eds) Jain A K and Manickavasagam R M, pp. 111116.

Bhattacharya A R 1999 Deformational regimes across the Kumaun Himalaya: A study in strain patterns; In: Geodynamics of the NW Himalaya (eds) Jain A K and Manickavasagam R M, Gond. Res. Gp Memoir, pp. 81-90.

Bhattacharya A R and Agarwal K K 1985 Mylonites from the Kumaun Lesser Himalaya; NEUES Jahrb. fur Mineral. 152 65-77.

Bose N and Mukherjee S 2015 Back structures (backfaults and backfolds) from collisional orogen: Field findings from Lesser Himalaya, Sikkim, India; In: 30th Himalaya Karakoram Tibet Workshop, p. 1314.

Célérier J, Harrison T M, Beyssac O, Herman F, Dunlap W J and Webb A A G 2009a The Kumaun and Garwhal Lesser Himalaya, India: Part 2. Thermal and deformation histories; Geol. Soc. Am. Bull. 121 1281-1297.

Célérier J, Harrison T M, Webb A A G and Yin A 2009b The Kumaun and Garwhal Lesser Himalaya, India: Part 1. Structure and stratigraphy; Geol. Soc. Am. Bull. 121 $1262-1280$.

Dubey A K 2014 Understanding an Orogenic Belt; 1st edn, Springer, Heidelberg, New York, Dordrecht, London.

Gansser A 1964 Geology of the Himalayas; Interscience, London, New York, Sydney.

Grasemann B, Stüwe K and Vannay J-C 2003 Sense and non-sense of shear in flanking structures; J. Struct. Geol. 25 19-34.

Jain A K and Anand A 1988 Deformational and strain patterns of an intracontinental collision ductile shear zone an example from the Higher Garhwal Himalaya; J. Struct. Geol. 10 717-734.

Jayangondaperumal R and Dubey A K 2001 Superposed folding of a blind thrust and formation of klippen: Results of anisotropic magnetic susceptibility studies from the Lesser Himalaya; J. Asian Earth Sci. 19 $713-725$.

Jayangondaperumal R, Dubey A K and Sen K 2010 Structural and magnetic fabric studies of recess structures in the western Himalaya: Implications for 1905 Kangra earthquake; J. Geol. Soc. India 75 225-238.

Jelinek V 1981 Characterization of the magnetic fabric of rocks; Tectonophys. $\mathbf{7 9}$ T63-T67.

Joshi M 1999 Evolution of the basal shear zone of the Almora Nappe, Kumaun Himalaya; In: Gondwana Research
Group Memoir (eds) Jain A K and Manickavasagam R M, pp. 69-80.

Joshi M and Tiwari A N 2009 Structural events and metamorphic consequences in Almora Nappe, during Himalayan collision tectonics; J. Asian Earth Sci. 34 326-335.

Joshi M and Tiwari A N 2004 Quartz C-axes and metastable phases in the metamorphic rocks of Almora Nappe: Evidence of pre-Himalayan signatures; Curr. Sci. 87 995-998.

Meigs A J, Burbank D W and Beck R A 1995 Middlelate Miocene (>10 Ma) formation of the Main Boundary Thrust in the western Himalaya; Geology 23 423-426.

Moharana A, Mishra A and Srivastava D C 2013 Deformation style in the Munsiari Thrust Zone: A study in the Madlakia-Munsiari-Dhapa section in north-eastern Kumaun Himalaya; Int. J. Earth Sci. 102 1837-1849.

Molnar P and Tapponnier P 1975 Cenozoic tectonics of Asia: Effects of a continental collision; Science $\mathbf{1 8 9}$ 419-426.

Mukherjee S 2012 Simple shear is not so simple! Kinematics and shear senses in Newtonian viscous simple shear zones; Geol. Mag. 149 819-826.

Mukherjee S and Koyi H A 2010a Higher Himalayan shear zone, Sutlej section: Structural geology and extrusion mechanism by various combinations of simple shear, pure shear and channel flow in shifting modes; Int. J. Earth Sci. 99 1267-1303.

Mukherjee S and Koyi H A 2010b Higher Himalayan Shear Zone, Zanskar Indian Himalaya: Microstructural studies and extrusion mechanism by a combination of simple shear and channel flow; Int. J. Earth Sci. 99 1083-1110.

Mukherjee S, Koyi H A and Talbot C J 2012 Implications of channel flow analogue models for extrusion of the Higher Himalayan Shear Zone with special reference to the out-of-sequence thrusting; Int. J. Earth Sci. 101 253-272.

Mukherjee S, Carosi R, van der Beek P, Mukherjee B K and Robinson D M 2015 Tectonics of the Himalaya: An introduction; Geol. Soc. London, Spec. Publ. 412 1-3.

Mulchrone K F and Mukherjee S 2016 Kinematics and shear heat pattern of ductile simple shear zones with slip boundary condition; Int. J. Earth Sci. 105(3) 1015-1020.

Nakata T 1989 Active faults of the Himalaya of India and Nepal; Geol. Soc. Am. Spec. Paper 232 243-264.

Pant P D, Chauhan R and Bhakuni S S 2012 Development of transverse fault along North Almora Thrust, Kumaun Lesser Himalaya, India: A study based on field and magnetic fabrics; J. Geol. Soc. India 79 429-448.

Passchier C W and Trouw R A 1996 Microtectonics; Springer, vol. 2, p. 82.

Petrovský E D and Kapička A 2006 On determination of the Curie point from thermomagnetic curves; J. Geophys. Res. Solid Earth 111 1-10.

Robinson D M and Pearson O N 2013 Was Himalayan normal faulting triggered by initiation of the RamgarhMunsiari thrust and development of the Lesser Himalayan duplex? Int. J. Earth Sci. 102 1773-1790.

Seeber L and Armbruster J G 1981 Great detachment earthquakes along the Himalayan Arc and long term forecasting; Earthq. Predict., pp. 259-277.

Srivastava P and Mitra G 1996 Deformation mechanisms and inverted thermal profile in the North Almora Thrust mylonite zone, Kumaon Lesser Himalaya, India; J. Struct. Geol. 18 27-39.

Srivastava P and Mitra G 1994 Thrust geometries and deep structure of the outer and lesser Himalaya, $\mathrm{Ku}$ maon and Garhwal (India): Implications for evolution of the Himalayan fold and thrust belt; Tectonics 13 89-109. 
Tarling D and Hrouda F 1993 Magnetic anisotropy of rocks; Springer, pp. 1-26.

Thakur V C 2013 Active tectonics of Himalayan Frontal Fault system; Int. J. Earth Sci. 102 1791-1810.

Thakur V C 1992 Geology of western Himalaya; Pergamon Press.

Tobgay T, McQuarrie N, Long S, Kohn M J and Corrie S L 2012 The age and rate of displacement along the Main Central Thrust in the western Bhutan Himalaya; Earth Planet. Sci. Lett. 319-320 146-158.

Trivedi J R, Gopalan K and Valdiya K S 1984 Rb$\mathrm{Sr}$ ages of granitic rocks within the Lesser Himalayan nappes, Kumaun, India; J. Geol. Soc. India 25 641654.

Trouw R A J, Passchier C W and Siersma D 2009 Atlas of Mylonites and related microstructures; Springer Science \& Business Media.

Valdiya K S 1980 Geology of Kumaun Lesser Himalaya; Wadia Institute of Himalayan Geology.

Valdiya K S 1998 Dynamic Himalaya; Universities Press.

Webb A A 2011 Cenozoic tectonic history of the Himachal Himalaya (northwestern India) and its constraints on the formation mechanism of the Himalayan orogen; Geosphere 71013.

MS received 15 October 2015; revised 29 January 2016; accepted 3 February 2016

Corresponding editor: M JAYANANDA 